\title{
Novel LDPE/EVA Nanocomposites with Silver/Titanium Dioxide Particles for Biomedical Applications
}

Gabriel Molina de Olyveira ${ }^{1}$, Ligia Maria Manzine Costa $^{1}$, Antônio José Felix de Carvalho ${ }^{2}$, Pierre Basmaji ${ }^{3}$ and Luiz Antonio Pessan ${ }^{1}$

1. Department of Materials Engineering-Polymers, Federal University of São Carlos-UFSCar,13565-905, São Carlos, SP, Brazil

2. Department of Materials Engineering, São Paulo University, 13566-590, São Carlos SP, Brazil

3. Innovatec's-Biotechnology Research and Development, Sao Carlos, SP, Brazil

Received: March 02, 2011 / Accepted: March 25, 2011 / Published: September 25, 2011.

\begin{abstract}
Nanocomposites with antimicrobial activity are of great interest nowadays and the development of titanium dioxide with these functional properties presents interest in academic and industrial sectors. An approach to develop PE nanocomposite containing $\mathrm{Ag}$ nanoparticles to have an antimicrobial effect is presented. To obtain such antimicrobial nanocomposites, LDPE/EVA were processed with $\mathrm{Ag}$ nanoparticles on $\mathrm{TiO}_{2}$ particles as inorganic carrier substance. Titanium dioxide nanoparticles (P-25) were covered with silver nanoparticles using Turkevich Method or citrate reduction method. The $\mathrm{Ag} / \mathrm{TiO}{ }_{2}$ nanoparticles were dispersed at concentration of $0.5 \mathrm{wt} \%, 0.8 \mathrm{wt} \%$ and $1 \mathrm{wt} \%$ in LDPE/ethylene vinyl acetate copolymer (EVA)- $(50 \% \mathrm{w} / \mathrm{w})$ at the melt state in a Haake torque Rheometer. Silver nanoparticles were characterized with UV-Vis Spectroscopy. The nanocomposites thus prepared were characterized through Ares Rheometer, Scanning Electronic Microscopy (SEM) and JIS Z 2801 antimicrobial tests to study the effects of the addition of nanoparticles on rheological properties, morphological behavior and antimicrobial properties. The results showed that incorporation of silver/titanium dioxide nanoparticles on nanocomposites obtained systems with different dispersions. $\mathrm{The} \mathrm{Ag} / \mathrm{TiO}{ }_{2}$ particles showed uniform distribution of $\mathrm{Ag}$ on $\mathrm{TiO}_{2}$ particles as observed by SEM-EDX and antimicrobial tests according to JIS Z 2801 shows excellent antimicrobial properties.
\end{abstract}

Key words: Nanocomposite, citrate reduction method, antimicrobial.

\section{Introduction}

Antimicrobial polymers have many applications in medical and packaging industries. The design of antimicrobial properties for a polymer depends on the application field of that polymer. Different types of antimicrobial additives based on silver are available in the market. It can kill the bacterial cell by reacting with sulfur containing functional groups in the cell and stops the respiratory function $[1,2]$. Additives in form of coatings are being used for different application, e.g., in refrigerator or in paints and varnishes. Coating plastic part with an antimicrobial material is a cost

Corresponding author: Gabriel Molina de Olyveira, Ph.D., research fields: polymer nanocomposites, bionanocomposites, bionanomedicine, bionanotechnology. E-mail: gmolyveira@yahoo.com.br. intensive process. Further disadvantages of such coatings are that these could get scratched easily and lose their antimicrobial effect in that area. Additives containing silver in powder form are also available in the market and these are mainly based on inorganic carrier substance zeolite [3-5]. Sondi et al. [6] investigated the antimicrobial activity of silver nanoparticles with ascorbic acid in the presence of a surfactant agent (Daxad 19) against E. coli. EDAX (energy dispersive spectroscopy) showed that silver nanoparticles were incorporated into the bacterial cell membrane and kill bacterial cells. Yao et al. [7] showed that $\mathrm{Ag} / \mathrm{TiO}_{2}$-coated silicon catheters possessed significant bactericidal activity against $E$. coli, P. aeruginosa and S. aureus.

Blending two or more polymers is an effective 
strategy to improve plastic material performance. The procedure is to use common polymers and to blend them in the melt to accomplish the required properties. However, most polymer pairs are immiscible and form a multiphase system leading to a more complex rheology [8]. In these systems, interfacial tension has a controlling role on both rheology and morphology since it influences the dispersed particle size as well as particle size distribution. LDPE/EVA shows a finely interconnected morphology at $50 \mathrm{wt} \%$ of EVA and the morphological observations can be attributed to the lower viscosity ratio and lower interfacial tension in the LDPE/EVA system. Besides, additive polymer EVA improves solubilization by partially binding the antimicrobial agents in the polymer matrix $[9,10]$.

In this study, a strategy to develop an antimicrobial product on the basis of $\mathrm{TiO}_{2}$ as inorganic carrier substance is explained. Silver nitrate was reduced by sodium citrate in the presence of poly (vinyl pyrrolidone) (PVP) and titanium dioxide resulting in nano- $\mathrm{Ag} / \mathrm{TiO}_{2}$ stabilized suspension. Each sample was centrifuged and the supernatant was removed, after that, the remains solid was dried at $100{ }^{\circ} \mathrm{C}$ for one hour in a vacuum oven then the $\mathrm{Ag} / \mathrm{TiO}_{2}$ nanoparticles were dispersed at concentration of $0.5,0.8,1 \mathrm{wt} \%$ in LDPE/ethylene vinyl acetate copolymer (EVA)- $(50 \%$ $\mathrm{w} / \mathrm{w})$ at the melt state in a Haake torque Rheometer.

\section{Experiment}

\subsection{Materials}

A low density polyethylene homopolymer with a melt flow index of $0.32 \mathrm{~g} / 10 \mathrm{~min}\left(190^{\circ} \mathrm{C} / 2.16 \mathrm{~kg}\right)$ and tradename of BF-0323 HC which was supplied by Braskem (Brazil). A EVA copolymer with a content of $9 \%$ vinyl acetate by weight and a melt flow index of 2 $\mathrm{g} / 10 \mathrm{~min}\left(190^{\circ} \mathrm{C} / 2,16 \mathrm{~kg}\right)$ was supplied as pellets by Triunfo Petrochemical (Brazil) under the tradename of Tritheva ${ }^{\circledR}$ TN 2020.

$\mathrm{TiO}_{2}$ nanoparticles (Degussa P-25), $\mathrm{AgNO}_{3}$ (HEXIS, ACS Reagent), Sodium Citrate (Synth) and PVP 40 (poly (vinyl pyrrolidone )-Sigma Aldrich) were used as received without further purification.

\subsection{Colloidal Synthesis}

For a typical procedure at room temperature and under stirring, silver nitrate solution $\left(2 \times 10^{-2} \mathrm{~mol} / \mathrm{L}\right)$ were heated to the boiling point and after sodium citrate $\left(3.6 \times 10^{-2} \mathrm{~mol} / \mathrm{L}\right)$ was added to the boiling solution with vigorous mechanical stirring. After fifteen minutes, PVP [poly(vinyl pyrrolidone)] solution was added $\left(3.75 \times 10^{-3} \mathrm{~mol} / \mathrm{L}\right)$. Then, $0.2 \mathrm{~g}, 0.5 \mathrm{~g}$ and 1 $\mathrm{g}$ of commercial Degussa $\mathrm{TiO}_{2}$ nanoparticles were dispersed in $100 \mathrm{~mL}$ of deionized water by using an ultrasonic treatment for approximately ten minutes and added in $\mathrm{Ag}$-solution resulting in nano- $\mathrm{Ag} / \mathrm{TiO}{ }_{2}$ stabilized suspension.

Each sample was centrifuged and the supernatant was removed, after that, the remains solid was dried at $100{ }^{\circ} \mathrm{C}$ for one hour in a vacuum oven.

\subsection{Nanocomposite Preparation}

All materials were vacuum dried for at least $12 \mathrm{~h}$ prior to melt processing. The antimicrobial nanocomposites were prepared in a Haake torque Rheometer model Rheomix 600p with CAM rotors at $190{ }^{\circ} \mathrm{C}$. The $\mathrm{Ag} / \mathrm{TiO}_{2}$ nanoparticles were dispersed at concentration of $0.5,0.8,1 \mathrm{wt} \%$ in LDPE/ethylene vinyl acetate copolymer (EVA)- $(50 \% \mathrm{w} / \mathrm{w})$ at the melt state in a Haake torque Rheometer.

\subsubsection{UV-Vis Spectroscopy}

Using the spectrometer VARIAN Caryn Scan 50, were taken from the spectra of UV-Vis of suspension of silver nanoparticles and silver/titanium dioxide nanoparticles in very dilute concentrations.

\subsubsection{Scanning Electronic Microscopy}

Scanning electronic microscopy images were performed on a PHILIPS XL30 FEG. The samples were covered with gold and silver paint for electrical contact and to perform the necessary images.

\subsubsection{Ares Rheometer}

A Rheometrics ARES rheometer with a convection oven purged with nitrogen gas was used. The 
frequency range used was $0.01-10 \mathrm{~Hz}$. The oven was preheated, and the rheological measurement was started $120 \mathrm{~s}$ after the sample was placed in the apparatus. Time sweep measurements were performed at a frequency of $1 \mathrm{~Hz}$.

2.3.4 Antimicrobial Test (JIS Z 2801)

Antibacterial activity is measured by quantifying the survival of bacterial cells which have been held in intimate contact for $24 \mathrm{~h}$ at $35{ }^{\circ} \mathrm{C}$ with a surface that contains an antibacterial agent. The antibacterial effect is measured by comparing the survival of bacteria on a treated material with that achieved on an untreated material.

\section{Results and Discussion}

\subsection{UV-Vis Spectroscopy}

Using the spectrometer VARIAN Caryn Sacan 50, were taken from the spectra of UV-Vis of suspension of silver nanoparticles in very dilute concentrations.

The absorption spectra of the silver nanoparticles are presented in Fig. 1. A weak band near $450 \mathrm{~nm}$ corresponds to the signal of silver nanoparticles [11-13].

\subsection{Scanning Electronic Microscopy (SEM)}

Silver/titanium dioxide nanoparticles were synthesized with sodium citrate like reductor agent and poly (vinyl pyrrolidone) like surfactant. With the help of a software image analyzer (IMAGEJ) we can draw graphs of the distribution of silver nanoparticles on titanium dioxide nanoparticles. The figure illustrates silver nanoparticles with different shapes, triangular, square and with a broad distribution, with most frequencies between 200 and $400 \mathrm{~nm}$ and between 1,200 and 1,400 $\mathrm{nm}$ as shown in Fig. 2. PVP (polyvinyl pyrrolidone) has some interesting and unique features, it donates their free electrons from atoms of oxygen and nitrogen to the sp orbital of silver ions, and thus form a complex of PVP-silver ions in aqueous solution and this promotes nucleation of metallic silver because the complex formed is more easily reduced by reducing agent (sodium citrate) than silver ions allowing silver ions receive more electron clouds of PVP that water $[14,15]$.

\subsection{Ares Rheometer}

We tested silver/titanium dioxide nanoparticles in LDPE/EVA polymer blends with oscillatory rheological analysis. When it was placed inorganics nanoparticles in the system, it can be observed in Fig. 3 that increase elastic and viscous modulus in the

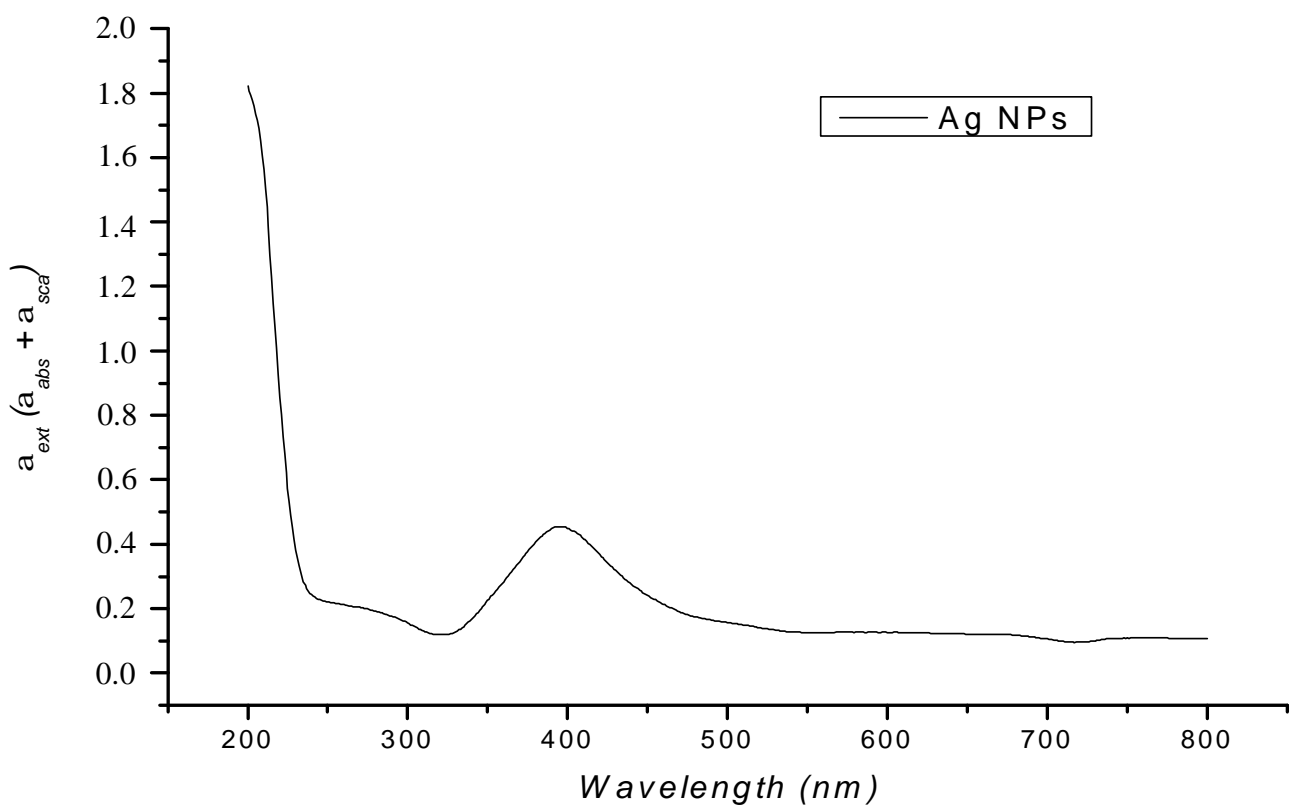

Fig. 1 Electronic spectra (UV-Vis): suspension of silver nanoparticles. 


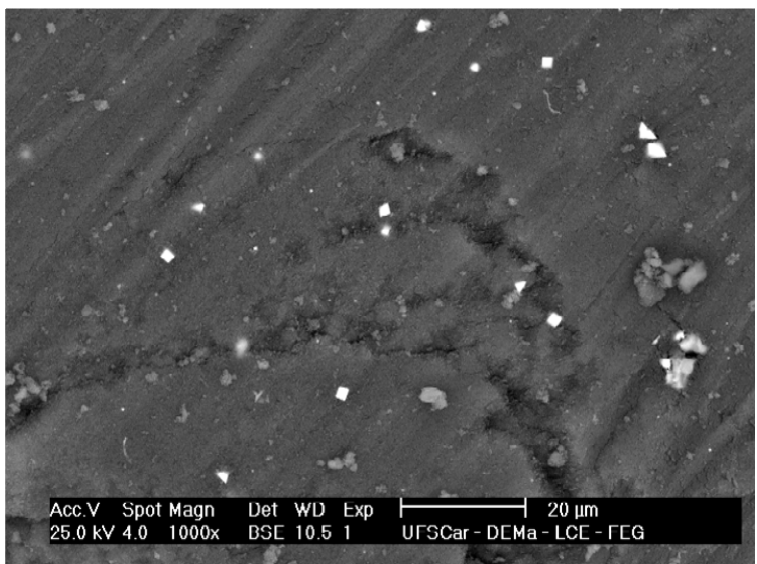

(a)

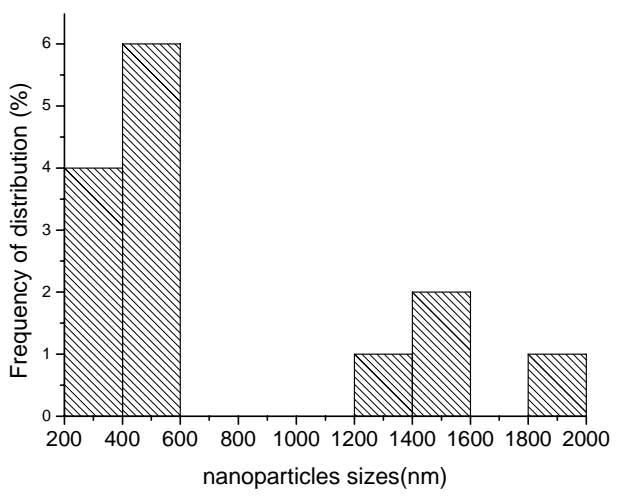

(b)

Fig. 2 (a) Silver nanoparticles on titanium dioxide; (b) Size distribution of silver nanoparticles on titanium dioxide nanoparticles.

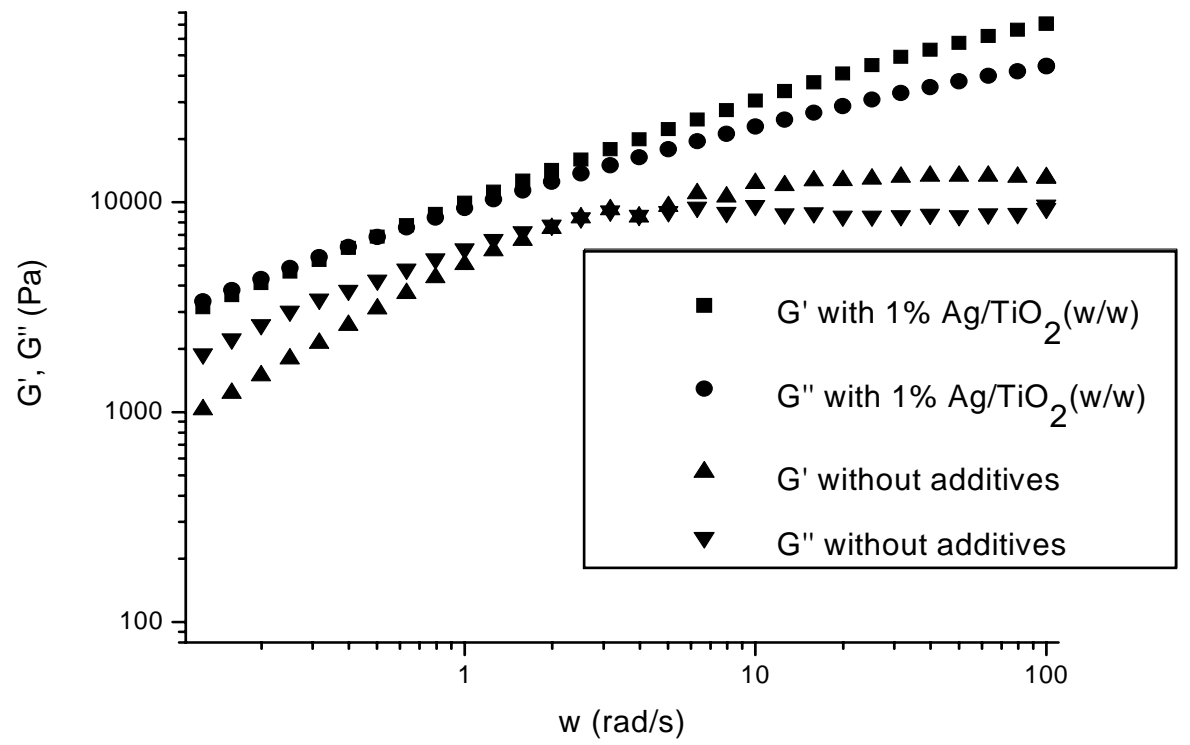

Fig. 3 G'(elastic modulus) and G’' (viscous modulus) versus oscillatory shear (rad/s).

LDPE/EVA blends, because inorganics nanoparticles prevent oscillatory macromolecular movements perfomed by rheometer shear thinning.

In Fig. 4, all systems has the inclination curves $\left(G^{\prime}\right.$, $\mathrm{G}$ ') ) proportional to $\mathrm{w}(\mathrm{rad} / \mathrm{s})$, every behaviors can't be characterized as pseudo-solid, which may be related to an inappropriate level of dispersion of the dispersed phase, probably due to the processing of the nanocomposite was carried out in a Haake rheometer where the shear rate is low compared to the extrusion and injection. We can note little differences from Figs. $4 \mathrm{~b}$ and $4 \mathrm{c}$, the addition of fillers/format of the fillers or the effect of the synthesis of nanoparticles has generated several rheological systems.

Oscillatory region in the rheological tests depends of relaxation time in the polymer system. In the typical range of frequencies available on most rheometers, say $10^{-2}$ to $10^{2} \mathrm{rad} / \mathrm{s}$, it is quite usual to see only two of the regions. The particular ones seen depend largely on the longest relaxation time, $\tau$ max, of the material being tested, so that if $\omega \tau$ max $\sim 1$, then the viscous and transition-to-flow regions are seen governed by the behavior of Maxwell where the response is predominantly viscous to be a region of low frequency. Thus, the addition of more fillers illustrated in Figs. $4 \mathrm{~b}$ and $4 c$ are more stable than Fig. $4 a$ because $G^{\prime \prime}>G^{\prime}$ at 


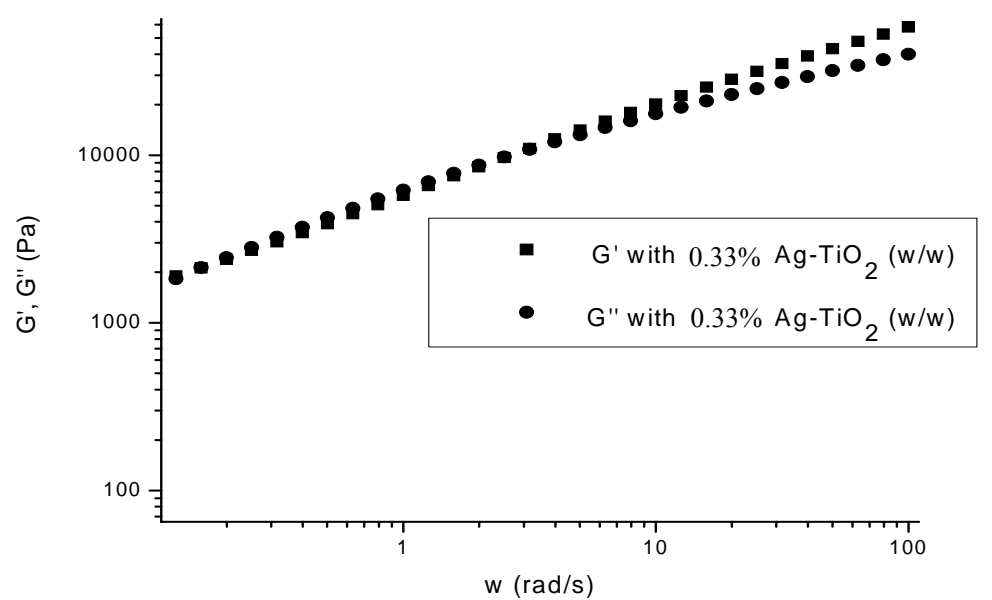

(a)

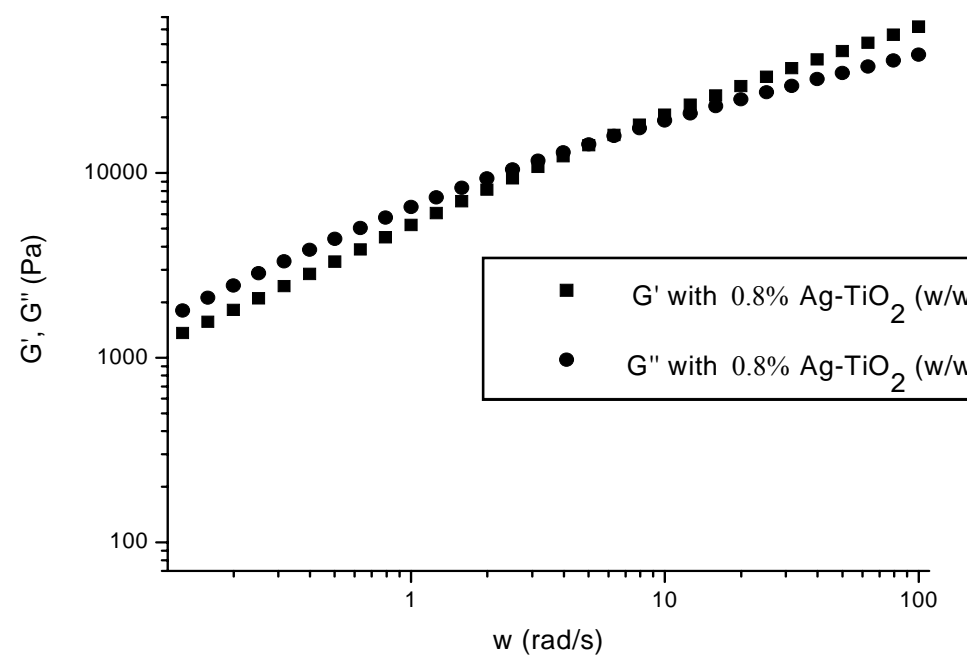

(b)

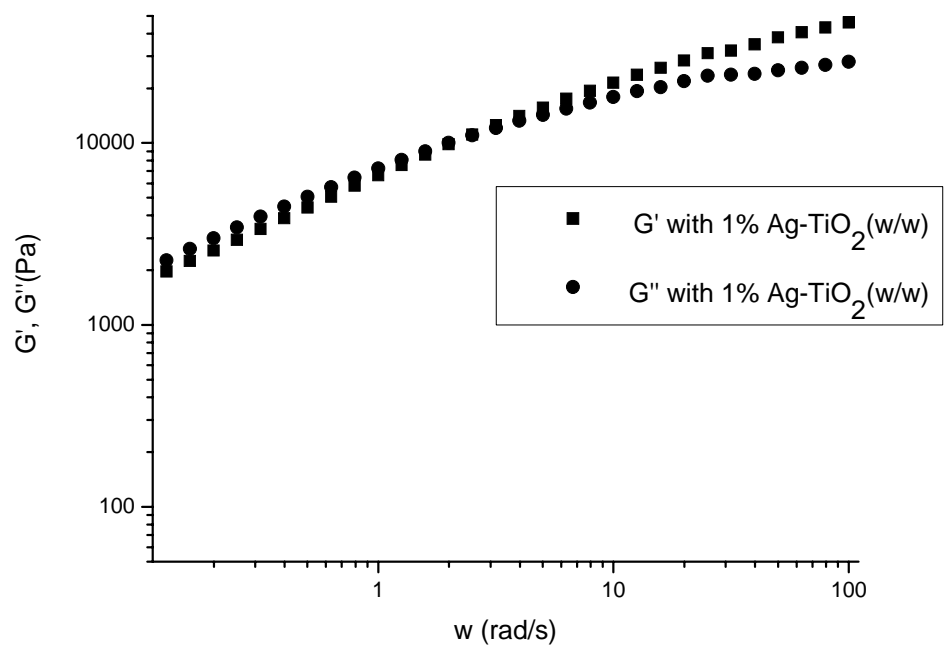

(c)

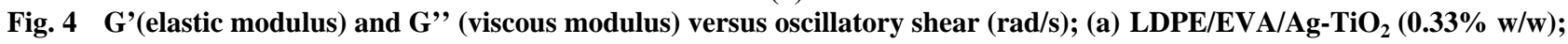
(b) $\mathrm{LDPE} / \mathrm{EVA} / \mathrm{Ag}-\mathrm{TiO}_{2}(0.8 \% \mathrm{w} / \mathrm{w})$; (c) LDPE/ EVA /Ag-TiO 2 (1\% w/w). 
Table 1 Antimicrobial Test (JIS Z 2801) in LDPE/EVA/Ag-TiO ${ }_{2}$ nanocomposites.

\begin{tabular}{llllr}
\hline Samples & $\begin{array}{l}\text { Colony formation units } \\
\text { in zero time Escherichia } \\
\text { coli }(\text { ATTC n } 8739)\end{array}$ & $\begin{array}{l}\text { Colony formation } \\
\text { units after contact } \\
\text { for } 24 \mathrm{~h}\end{array}$ & $\begin{array}{l}\text { Logarithmic } \\
\text { reduction }\end{array}$ & \% Reduction \\
\hline $01\left(0.5 \% \mathrm{Ag} / \mathrm{TiO}_{2} / \mathrm{LDPE} / \mathrm{EVA}\right)$ & $4.6 \times 10^{5}$ & $1.2 \times 10^{5}$ & 0.58 & 73.91 \\
$02\left(1 \% \mathrm{Ag} / \mathrm{TiO}_{2} / \mathrm{LDPE} / \mathrm{EVA}\right)$ & $4.6 \times 10^{5}$ & $4.7 \times 10^{4}$ & 0.99 & 89.78 \\
$03(\mathrm{LDPE}$ pure $)$ & $4.6 \times 10^{5}$ & $4.3 \times 10^{5}$ & 0.03 & 6.52 \\
\hline
\end{tabular}

the beginning of the test.

\subsection{Antimicrobial Test (JIS Z 2801)}

In antimicrobial, E.coli bacterial colony was tested: Escherichia coli (ATTC n'8739). Escherichia coli is a gram-negative rod-shaped bacterium that is commonly found in the lower intestine of warm-blooded organisms (endotherms) and has an outer complex of lipopolysaccharides, phospholipids and lipopolyproteins. In Table 1, we can observe that gramnegative Escherichia coli with an outer complex of lipopolysaccharides, phospholipids and lipopolyproteins isn't resistant to polymer nanocomposite and that a larger amount of antimicrobial agent is better in kill superficial bacteria.

\section{Conclusions}

In this study, an approach to develop a process for the preparation of antimicrobial polyethylene nanocompositesis discussed. Morphological analysis of the compounded materials (silver-titanium dioxide nanoparticles) showed partial dispersion of $\mathrm{TiO}_{2}$ nanoparticles and the detachment of Ag-nanoparticles from the $\mathrm{TiO}_{2}$ particles at different parts of the compounded materials. UV-Vis Spectroscopy analyses confirm the presence of silver in the form of $\mathrm{Ag}^{0}$ obtained of colloidal synthesis.

The effect of different parameters on the antimicrobial nanocomposites which are compounded in a Haake rheometer was analyzed. Ares rheometer showed rheological instability systems characterized as pseudo-solid, which may be related to an inappropriate level of dispersion of the dispersed phase. In antimicrobial test, a large amount of antimicrobial fillers showed linear increase of antimicrobial properties. In future work, an ideal filler amount will be studied to obtain an economic and excellent antimicrobial nanocomposites.

\section{References}

[1] J.P. Guggenbichler, Foreign-body associated infections in intensive care therapy and prevention, Antibiotics Monitor 3 (2004).

[2] H. Zenji, H. Shigetaka, I. Hiroo, N. Saburo, T. Kenichi, Y. Keio, Zeolite particles retaining silver ions having antibacterial properties, Patent Nr. 4 (1990) 898-911.

[3] J.P. Guggenbichler, A. Hirsch, Production of antimicrobial plastic articles, especially catheters, involves pretreatment with colloidal metal, especially colloidal silver, before the final moulding process, Patent Nr. DE10013248, 2001.

[4] S. Khare, M. Moneke, N. Plachkov, R. Hempelman, Development of silver based PE-nanocomposites for antimicrobial applications, Annual Technical Conference Proceedings, 2006.

[5] M.H. Baumann, The impact of biotechnology and nanotechnology on the chemical and plastics industries, Annual Technical Conference Proceedings, 2004.

[6] I. Sondi, D.V. Goia, E. Matijevic, Preparation of highly concentrated stable dispersions of uniform silver nanoparticles, Journal of Colloid and Interface Science 260 (2003) 75-81.

[7] Y. Yao, Y. Ohko, Y. Sekigushi, A. Fujishima, Y. Kubota, Self-sterilization using silicone catheters coated with Ag and $\mathrm{TiO}_{2}$ nanocomposite thin film, J. Biomed. Mater. Res. B: Appl. Biomater. 2 (2008) 453-460.

[8] G. Takidis, D.N. Bikiaris, G.Z Papageorgiou, D.S. Achilias, I. Sideridou, Compatibility of low density polyethylene/poly (ethylene-co-vinyl acetate) binary blends prepared by melt mixing, Journal of Applied Polymer Science 90 (2003) 841-852.

[9] H.A. Khonakdar, S.H. Jafari, A. Yavari, A. Asadinezhad, U. Wagenknecht, Rheology, morphology and estimation of interfacial tension of LDPE/EVA and HDPE/EVA blends, Polymer Bulletin 54 (2005) 75-84.

[10] H.A. Khonakdar, U. Wagenknecht, S.H. Jafari, R. Hassler, 
H. Eslami, Dynamic mechanical properties and morphology of polyethylene/ethylene vinyl acetate copolymer blends, Advances in Polymer Technology 23 (2004) 307-315.

[11] E. Matijevic, Preparation and properties of uniform size colloids, Chem. Mater. 5 (1993) 412.

[12] J.R. Morones, J.L. Elechiguerra, A. Camacho, K. Holt, J.B. Kouri, J.T. Ramırez, et al., The bactericidal effect of silver nanoparticles, Nanotechnology $16 \quad$ (2005) 2346-2353.
[13] N.N. Martinez, G.A.M. Castanon, P.A. Aragon, F.M. Gutierrrez, J.R.M. Mendoza, F. Ruiz, Characterization of silver nanoparticles synthesized on titanium dioxide fine particles, Nanotechnology 19 (2008) 65711.

[14] G. Carotenuto, G.P. Pepe, L. Nicolais, Preparation and characterization of nano-sized Ag/PVP composites for optical applications, Eur. Phys. J. B 16 (2000) 11-17.

[15] Y. Sun, B. Mayers, T. Herricks, Y. Xia, Polyol synthesis of uniform silver nanowires: a plausible growth mechanism and the supporting evidence, Nano Letters 3 (2003) 955 . 